\title{
The relationship between mindfulness and individual adaptability in dynamic work contexts
}

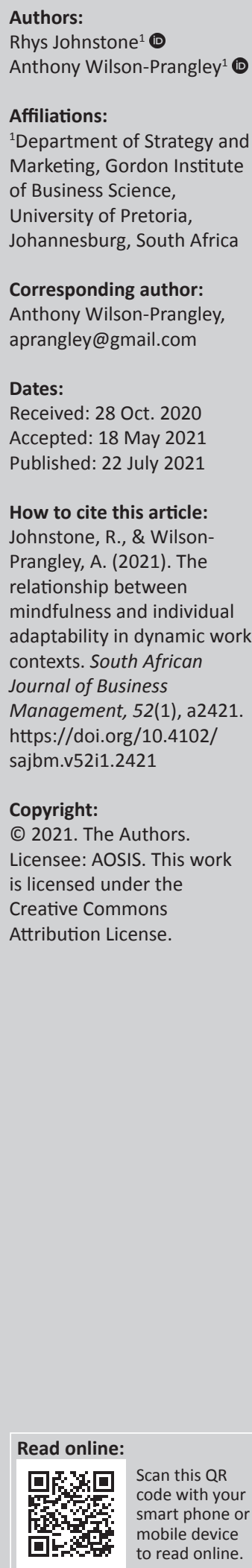

Purpose: Individual adaptability has been proposed as a source of adaptive performance. This is an increasingly important performance dimension in dynamic contexts. Mindfulness has been demonstrated to improve dimensions of performance and well-being in the workplace, but the underlying mechanisms of this relationship are not well understood. Addressing this gap, the study hypothesised a link between mindfulness and individual adaptability in dynamic work contexts.

Design/methodology/approach: One hundred and ninety-eight individuals in dynamic work contexts completed a self-rating survey that measured mindfulness and a multifactor measure of individual adaptability. These data were then analysed to test the hypotheses developed.

Findings/results: A significant positive relationship was found between mindfulness and five dimensions of adaptability (work-stress adaptability, uncertainty adaptability, crisis adaptability, creative problem-solving adaptability and learning adaptability). Interpersonal and cultural adaptability were not found to correlate with mindfulness.

Practical implications: This study demonstrates that mindfulness is not simply a stress management skill but is correlated with key aspects of adaptability such as learning and problem-solving. The findings suggest it may be possible to enhance individual adaptability through Mindfulness-Based Interventions and thus support adaptive performance.

Originality/value: This study is original in examining the relationship between mindfulness and individual adaptability in the workplace. This study highlights how different methods of operationalising mindfulness can lead to different conclusions. It points to the value of broader measures of mindfulness that capture attitudinal dimensions. In addition, as few studies on mindfulness in African contexts have been performed, this study broadens the research contexts in which mindfulness is understood.

Keywords: mindfulness; individual adaptability; adaptive performance; dynamic contexts; uncertainty.

\section{Introduction}

Dynamic work contexts arise from technological advances, globalisation and changing customer preferences which create opportunities but can outpace traditional approaches to change (Kotter, 2012), threaten the sustainability of firms (Teece, 2007) and polarise the labour market (Autor, 2015). The global spread of coronavirus disease 2019 (COVID-19) has accelerated organisational uncertainty (Stephens et al., 2020) and illustrated how quickly workplace dynamics can change (Venkatesh, 2020).

Ongoing, bottom-up adaptation by workers and managers, rather than top-down intervention, has been proposed as one response to dynamic work contexts (Wee \& Taylor, 2018). Individual adaptability, the ability of individuals to initiate or respond to change (Baard, Rench, \& Kozlowski, 2014; Ployhart \& Bliese, 2006) is an important microfoundation of dynamic capability. Developing it can support sustainable organisational competitiveness in such contexts (Helfat \& Peteraf, 2015; Ployhart \& Moliterno, 2011).

The antecedents of individual adaptability are not well understood (Huang, Ryan, Zabel, \& Palmer, 2014). There is evidence for the role of meta-awareness, resilience, positive affect and prosocial behaviour as some of the potential sources (Jundt, Shoss, \& Huang, 2015). Mindfulness has been found to promote meta-awareness, resilience, positive affect and pro-social behaviour, suggesting a link to adaptability. The contribution of this study is to investigate the relationship between mindfulness and individual adaptability. 
Mindfulness has been defined as 'awareness that emerges through paying attention on purpose, in the present moment, and nonjudgmentally' (Kabat-Zinn, 2003, p. 145). A secular form of mindfulness, inspired by Buddhist practices, has emerged (Lindahl, Fisher, Cooper, Rosen, \& Britton, 2017) and has been a subject of academic study for 40 years. This was initially in the clinical, neuroscientific and psychological fields, but more recently in organisational science, leadership and management (Good et al., 2016).

Mindfulness has been found to be beneficial as part of programmes to manage stress and pain (Kabat-Zinn, 2003), depression and anxiety (Segal, Williams, Teasdale, \& Gemar, 2002) and addiction (Brewer et al., 2009). Mindfulness has also been demonstrated to increase positive affect, pro-social behaviour, physical health and cognition in healthy individuals (Brown, Ryan, \& Creswell, 2007). Workplace studies have found that mindfulness can improve performance and well-being in individuals (Dane \& Brummel, 2014; Lomas et al., 2017; Lyddy, Good, Bolino, Thompson, \& Stephens, in press; Mesmer-Magnus, Manapragada, Viswesvaran, \& Allen, 2017; Montani, Dagenais-Desmarais, Giorgi, \& Grégoire, 2018).

As a result of its association with meta-awareness, resilience, positive affect and pro-social behaviour, it is possible that mindfulness is related to individual adaptability and therefore supports adaptive performance. Mindfulness may also mitigate some of the negative impact of the demand for constant adaptation in the workplace by increasing resilience to change and improving the stress response (Braun, Hayes, DeMuth, \& Taran, 2017; Lomas et al., 2017).

Individuals appear to have different levels of trait mindfulness (Brown \& Ryan, 2003); however, mindfulness is an inherent state of human awareness, which can be experienced without any special training or technique. Mindfulness can also be developed through certain practices and its effects have been found to continue after an intervention (Crane et al., 2017; Singer \& Engert, 2019).

Mindfulness may enable individual adaptability. The demand for adaptability can place a great deal of stress on employees and negatively impact their performance and sense of well-being (Braun et al., 2017; Cullen, Edwards, Casper, \& Gue, 2014). It is estimated that between five and eight percent of total United States (US) health care costs and up to 120000 annual deaths are because of workplace stress (Goh, Pfeffer, \& Zenios, 2016). More than $50 \%$ of all sick days in the United Kingdom are now ascribed to poor mental health (Lomas et al., 2017).

Individual adaptability in the face of continuous change therefore represents an opportunity and threat to both firms and employees. There is a pressing need to develop the theory and practice of individual adaptability in a way that is sustainable for both firms and employees.
Adaptive performance (Allworth \& Hesketh, 1999; Griffin, Neal, \& Parker, 2007) is now recognised as a dimension of performance alongside task and context performance (Bergman, Donovan, Drasgow, Overton, \& Henning, 2008; Motowidlo, Borman, \& Schmit, 1997). Adaptive performance has been described using an eight-dimensional taxonomy of behaviours that characterise adaptation (Pulakos, Arad, Donovan, \& Plamondon, 2000).

Ployhart and Bliese (2006) proposed individual adaptability as a composite variable which can be used to predict adaptive performance and which mediates the effects of individual differences. They also proposed a second-order factor structure for individual adaptability that accounts for the eight behavioural dimensions of adaptive performance (Jundt et al., 2015). Of these second-order abilities, seven are relevant to the present research: work-stress adaptability; crisis adaptability; uncertainty adaptability; learning adaptability; problem-solving adaptability; inter-personal adaptability; and cultural adaptability (Ployhart \& Bliese, 2006).

This is the first study to look at the relationship between mindfulness and individual adaptability. This is a relevant contribution given the uncertain, dynamic nature of work contexts today.

\section{Literature review Mindfulness in the workplace}

Mindfulness is a state of awareness that is valued in the contemplative traditions of many religions (Brown et al., 2007). However, the primary source for modern mindfulness comes from the Buddhist canon (Bishop et al., 2004; KabatZinn, 2003). Through a process of interaction over several generations, many of these Buddhist traditions have begun to be practiced and taught beyond their geographical and religious origins. Out of this process, both a 'Western' Buddhist tradition and a secular or scientific approach to the practice and the study of mindfulness have developed (Lindahl et al., 2017). The number of scientific papers about mindfulness published per year has increased from about 100 in the year 2000 to over a thousand in the year 2015 (Van Dam et al., 2018).

Mindfulness training is now conducted in business schools (King \& Badham, 2020; Kuechler \& Stedham, 2018), organisations such as Google and Apple (Glomb, Duffy, Bono, \& Yang, 2011) and even the US Army (Jha, Stanley, Kiyonaga, Wong, \& Gelfand, 2010). The initial focus of mindfulness studies was in the fields of medicine, psychology and neuroscience; however, there has been a recent surge of interest from management, organisational and leadership researchers (Johnson, Park, \& Chaudhuri, 2020; Good et al., 2016; Hyland, Andrew Lee, \& Mills, 2015; Montani et al., 2018). It is within this scientific approach to mindfulness in work settings that the present research is situated. 
Scholars of mindfulness have discerned two conceptual constituents (attention and attitude; Bishop et al., 2004) or three operational mechanisms (intention, attention and attitude; Shapiro, Carlson, Astin, \& Freedman, 2006). Another common characterisation of the mindful state is as experiential and non-attached, rather than narrative, conceptual and egodriven (Brown et al., 2007). Mindfulness is not synonymous with meditation which can take many forms unrelated to mindfulness. Mindfulness describes a non-discriminating, open quality of awareness (Csikszentmihalyi, 2014).

Importantly, mindfulness is a natural state of mind that can be increased through certain practices (Crane et al., 2017) and these effects may continue after training. In other words, mindfulness is not only a temporary state, nor is it a fixed trait, limited to certain individuals. Rather it is a traitlike skill that can be taught and developed. Pre-existing trait-level mindfulness can be increased to a new stable level through practice. Neuroplasticity, including changes in the structure and function of regions of the brain involved in attention, emotional regulation and self-awareness, such as the amygdala and the pre-frontal cortex, may underpin this 'trainable' aspect of mindfulness (Tang, Hölzel, \& Posner, 2015).

Mindfulness is defined in the management literature as a state of awareness where there is increased stability, control and efficiency of attention, which improves regulation of functional dimensions - cognition, emotion, physiology and behaviour, with positive impacts on aspects of performance, well-being and interpersonal relationships (Good et al., 2016). This unidimensional definition of mindfulness (focussing on attention) is operationalised by the Mindful Attention Awareness Scale (MAAS; Brown \& Ryan, 2003). It does not include the 'attitudinal' or 'intentional' dimensions emphasised in other literatures (Bishop et al., 2004; Crane et al., 2017; Kabat-Zinn, 2003; Shapiro et al., 2006). Given the broad support for MAAS in empirical studies of mindfulness, this scale was selected along with Good et al.'s (2016) framework for the study.

Mindfulness has been found to help manage chronic pain (Kabat-Zinn, 1982), and prevent depression relapse (Segal et al., 2002). It is used in other therapeutic modalities such as acceptance and commitment therapy and dialectical behaviour therapy (Brown et al., 2007). People who score higher on mindfulness tests report higher levels of subjective well-being and lower levels of emotional turbulence (Brown \& Ryan, 2003). Mindfulness is also associated with better physical health, including better sleep (Hülsheger, Walkowiak, \& Thommes, 2018). It is also linked to the inclination to exercise more, less avoidance of health issues and reduced self-medication with drugs and alcohol (Hue \& Lau, 2015).

There is a growing body of evidence from workplace studies that mindfulness-based interventions (MBIs) can reduce mental health problems in the workplace (e.g. stress, burnout, anxiety and anger) and enhance measures of well-being, including resilience and job satisfaction (Lomas et al., 2017; Spinelli, Wisener, \& Khoury, 2019). Mindfulness has also been found to enhance work relationships, perhaps through increased empathy and ability to create distance from egocentred thought processes and narrative-style sense-making (Brown et al., 2007). Most recent research supports a positive link between mindfulness and workplace performance. In a 2017 review of empirical studies of mindfulness, specifically in the workplace, 37 out of 43 longitudinal studies found evidence for an improvement in performance after an MBI, whilst 17 cross-sectional, non-intervention studies found a positive association between mindfulness and performance (Lomas et al., 2017).

There is less agreement on which aspects of performance are improved. The same article listed 26 different measures of performance improvements across the various studies reviewed (Lomas et al., 2017). However, some authors have attempted to hone in on a more definitive list of performance dimensions. In a 2016 integrative review of existing empirical research, mindfulness was found to impact four performance aspects: improved job and task performance, more ethical and pro-social behaviour, less deviance and better attention to safety issues (Good et al., 2016). In a review of thousands of mindfulness studies, mindfulness was found to have four benefits that are relevant to individual performance in the workplace: stronger focus, staying calmer under stress, better memory and good corporate citizenship (Goleman \& Davidson, 2017). Mindfulness has also been linked to intrinsic motivation in the workplace (Donald et al., 2020).

Recent work has also distinguished mindfulness from other constructs with positive workplace implications. A study of workers in the service industry found that in dynamic work environments, mindfulness facilitates job performance independent of engagement. Mindfulness was also found to be negatively related with intention to turnover (Dane \& Brummel, 2014). Mindfulness may also have specific leadership benefits (King \& Badham, 2020; Roche, Haar, \& Luthans, 2014) over and above general workplace performance. In a 2017 Australian study of 84 senior managers, those with higher mindfulness were found to score higher on core leadership, self-mastery skills and also on leadership organisational-transformation measures, as rated by their immediate managers (King \& Haar, 2017).

\section{Individual adaptability in dynamic contexts}

The resource-based view of the firm holds that organisations create competitive advantage by developing distinctive capabilities (Wernerfelt, 1984). However, increasing competition, globalisation, the rate of technological change and consumer access to information are constantly eroding this advantage. This forces firms to adapt at an increasing rate. Dynamic capabilities are required to constantly innovate and remain competitive (Eisenhardt \& Martin, 2000; Teece, Pisano, \& Shuen, 1997). Organisations need to select, train, 
develop and performance-manage individuals in such a way as to create and nurture the microfoundations of these dynamic capabilities (Helfat \& Peteraf, 2015; Teece, 2007). Alignment is required between the capabilities and performance of individuals, and desired organisational outcomes in dynamic contexts (Ployhart \& Moliterno, 2011). This study examined the individual performance elements of dynamic capabilities. For this reason, job performance and individual adaptability are substantively discussed next. After this, the key variables of individual adaptability are discussed in the hypothesis development section.

Job performance theory holds that performance can be measured as the aggregate of all behaviour relevant to organisational objectives (Campbell, 1990). Importantly, this theory of job performance focusses on behaviour, rather than results, because there are other factors that may affect organisational results which are not related to an individual's performance. The theory also distinguishes between behaviours that support and those that impede the organisation from achieving its objectives (Campbell, McCloy, Oppler, \& Sager, 1993). Motowidlo et al. (1997) examined the relationship between individual differences (such as personality and cognitive ability) and performance and found that there is not a direct relationship. Rather the influence of individual differences on performance is mediated by other variables such as knowledge and skills. Campbell et al. (1993) found a similar pattern and listed the mediating variables as declarative knowledge, procedural knowledge, skill and motivation. These findings can be summarised as follows: individual differences $\rightarrow$ mediating variable $\rightarrow$ job performance.

Other theorists distinguish between two dimensions of job performance - task performance and contextual performance - on the basis that the antecedents of these two dimensions (the individual differences and mediating variables) were not the same (Motowidlo \& Van Scotter, 1994). Task performance includes behaviours to carry out the technical content of the work to be carried out, such as sales or administration, whilst contextual performance included behaviours that are responsive to the interpersonal, cultural and structural dynamics in the organisation (Motowidlo et al., 1997). It is argued that task performance is largely predicted by cognitive ability, whilst contextual performance is largely predicted by personality. Later empirical studies supported Motowidlo's theory of the differences between task and contextual performance (e.g. Bergman et al., 2008). This distinction between performance dimensions based on their antecedents is crucial in developing our argument.

Similar to the argument for discriminating between task and contextual performance, it has been reasoned that the need for continuous adaptation by individuals to dynamic job requirements requires a third performance dimension, adaptive performance (Allworth \& Hesketh, 1999; Griffin et al., 2007). Adaptive performance can be defined as 'performance-directed behaviors individuals enact in response to, or anticipation of, changes relevant to job-related tasks' (Jundt et al., 2015, p. S55). It is predicated on a specific set of individual differences (personality and cognitive abilities) and, like task and contextual performance, may be mediated by specific variables.

Pulakos et al. (2000) used a critical incident technique to develop an eight-dimension taxonomy that defined the adaptive performance requirements of jobs. These performance dimensions were as follows: handling work stress; handling crisis or emergency situations; dealing with uncertain or unpredictable work situations; learning work tasks, technologies and procedures; solving problems creatively; demonstrating inter-personal adaptability; demonstrating cultural adaptability and demonstrating physically orientated adaptability. The 'job adaptability index' was also developed by the same team - this was a measure designed for self-reporting and supervisor rating of adaptive performance behaviours. This was a useful tool for performance management; however, it did not allow researchers to examine the sources of adaptive performance, as required for staff selection and training.

This study is focussed on examining such predictors of adaptive performance that lie in the individual differences between and within individuals, and other antecedents of adaptive performance (Allworth \& Hesketh, 1999; LePine, Hollenbeck, Ilgen, \& Hedlund, 1997; Ployhart \& Bliese, 2006). To distinguish these antecedents of adaptive behaviour from performance per se, reviewers of the literature, including Baard et al. (2014) and Jundt et al. (2015), have encouraged researchers to distinguish individual adaptability (an individual differences construct that predicts behaviour) from adaptive performance (a dimension of job performance which is a set of relevant behaviours).

Ployhart and Bliese (2006) developed the individual adaptability theory (I-ADAPT theory) and the individual adaptability measure (I-ADAPT-M) to describe and measure the individual differences that could predict adaptive performance along Pulakos's eight dimensions. Ployhart defined individual adaptability as representing 'an individual's ability, skill, disposition, willingness and/or motivation, to change or fit different task, social and environmental features' (p. 13). The I-ADAPT theory holds that individual adaptability is a higher order construct with eight lower-order dimensions: work-stress adaptability; crisis adaptability; uncertainty adaptability; learning adaptability; problem-solving adaptability; inter-personal adaptability; cultural adaptability and physical adaptability. These dimensions and key research around their nature are discussed in the hypothesis development section. Adaptability emerges from a set of more distal knowledge, skills, abilities and other characteristics (KSAOs) that most contribute to adaptability, creating a 'composite KSAO', individual adaptability. These KSAOs (Krumm, Kanthak, Hartmann, \& Hertel, 2016) include cognitive ability, personal traits, preferences and stress and coping skills. 
Each adaptability sub-dimension is a mixture of different KSAOs, in different proportions. For example, the model predicts emotional stability to be more strongly related to crisis adaptability than to learning adaptability (Ployhart \& Bliese, 2006).

In this study, mindfulness was proposed as one such KSAO, and the study tested this empirically by examining the relationships between mindfulness and seven of the subdimensions of adaptability. Physical adaptability was excluded as it was not considered a relevant characteristic of office workers in dynamic work environments, and was actually developed to measure the ability of soldiers and other government agents to adjust to harsh fieldwork. Ployhart and Bliese's (2006) proposed latent factor structure for individual adaptability has only been tested empirically in one study, with inconclusive results (Hamtiaux, Houssemand, \& Vrignaud, 2013), and this study therefore also examined this second-order construct and explored its relationship with mindfulness. The key hypotheses were developed after examining the literature on mindfulness.

\section{Hypothesis development}

The literature review discussed previously shows that mindfulness and individual adaptability are important dimensions of adaptive performance and that adaptive performance is key to dynamic capabilities at the firm level. In addition, the review has demonstrated that individual adaptability and mindfulness may be related. The literature review identifies this as a crucial gap in the current scholarship. More specifically, a set of seven individual-level adaptability variables may be linked with mindfulness. These potential relationships are tested empirically in this study. Each of these variables is discussed in detail next, followed by the relevant proposed hypothesis. Work-stress adaptability is characterised by resilience under time pressure, high workload or difficult circumstances and by the ability to exhibit constructive behaviours, such as resisting, overreacting or blaming others under pressure (Braun et al., 2017; Ployhart \& Bliese, 2006). By decoupling an individual's sense of identity from an experience (e.g. a verbal attack by a hostile customer), mindfulness may be able to increase work-stress adaptability in individuals (Brown et al., 2007). Mindfulness may reduce emotional reactivity to negative events (Hülsheger, Alberts, Feinholdt, \& Lang, 2013). Further, mindfulness may shorten the lifecycle of emotions, reducing the time taken for an emotion to peak and return to baseline (Siegel, 2010). It is therefore proposed that:

H1: Mindfulness is positively related to work-stress adaptability.

Crisis adaptability refers to the ability to handle emergency situations appropriately, including identifying the issue and reacting swiftly, as well as remaining calm and focussed in an emergency (Jundt et al., 2015). Mindfulness has been associated with greater equanimity when faced with unpleasant or challenging events, and the ability to remain engaged without excessive reactivity (Lomas et al., 2017).
Mindfulness may also assist with the physiological reaction to a crisis, for example, in regulating blood pressure (Brown et al., 2007). The ability to focus during a crisis, and allocate attention efficiently at will, is also a noticeable quality of more mindful individuals (Lyddy \& Good, 2017). It is therefore proposed that:

H2: Mindfulness is positively related to crisis adaptability.

Uncertainty adaptability is the ability to remain effective in ambiguous or changing situations; to be able to make decisions without having the full picture and being able to change course if necessary (Cullen et al., 2014). Dane's (2011) contingency theory of mindfulness explained the role of mindfulness in widening attentional breadth, which may be valuable for experts in novel situations, especially in dynamic environments. By stabilising attention and increasing cognitive flexibility, it is possible that mindfulness has a buffering effect which protects performance from environmental changes and discontinuity (Jha et al., 2015). It is therefore proposed that:

H3: Mindfulness is positively related to uncertainty adaptability.

Learning adaptability is characterised by enthusiasm for and pro-active seeking out of new knowledge and training in new processes, technology or job requirements. It also suggests a capacity to learn new skills and tasks (Bohle Carbonell, Könings, Segers, \& Van Merriënboer, 2016; Le Pine, Colquitt, \& Erez, 2000). Mindfulness may be related to learning: There is evidence that it is positively related to greater working memory capacity (Jha et al., 2010; Ruocco \& Direkoglu, 2013) and to increased fluid intelligence and cognitive flexibility (Good et al., 2016). The relationship between mindfulness and self-regulation (Glomb et al., 2011) may also enable reflective learning where mindfulness enables conscious choice of new behaviours over mindless automatic responses, producing more adaptive outcomes. It is therefore proposed that:

H4: Mindfulness is positively related to learning adaptability.

Problem-solving adaptability involves the ability to use fresh perspectives and integrative approaches to solve problems creatively and to generate novel solutions. Individuals with this ability are able to use limited resources and think 'outside the box' to find solutions where others might not (Baard et al., 2014; Good, 2014). Mindfulness has been linked to creativity and divergent and convergent thinking (Colzato, Ozturk, \& Hommel, 2012), as well as insight problem solving (Ostafin \& Kassman, 2012). The mechanisms at work are likely the broad attentional breadth of mindfulness and the ability to let go of previous concepts and emotions (KabatZinn, 2003). Mindful individuals may also be more likely to work past obstacles and to set challenging goals (Glomb et al., 2011), and a link has been found between mindfulness and fluid intelligence (Lyddy \& Good, 2017). It is therefore proposed that:

H5: Mindfulness is positively related to problem-solving adaptability. 
Interpersonal adaptability is the ability of individuals to be flexible and open-minded when working with a diverse range of other people; to be open to feedback from others and develop good working relationships (Ployhart \& Bliese, 2006; Pulakos et al., 2000). Some theoretical conceptions of mindfulness include an empathetic attitudinal component (Bishop et al., 2004; Crane et al., 2017; Kabat-Zinn, 2003; Shapiro et al., 2006). Empirical research suggests that mindfulness can improve interpersonal relationships via enhanced empathy and better regulation of emotions (Hülsheger et al., 2013) and behaviour (Mesmer-Magnus et al., 2017). Mindful individuals have been found to be less judgmental of others and more charismatic (Glomb et al., 2011). These positive outcomes are seen at both the dyadic level, for example, in relationships between supervisors and team members and also within teams through improved communication quality, relationship quality and empathy (King \& Haar, 2017). It is therefore proposed that:

H6: Mindfulness is positively related to inter-personal adaptability

Cultural adaptability includes the ability or inclination to try to understand or learn about people or groups from different cultures. It could also include taking active steps to adjust behaviours or appearances to fit in or comply with different cultural norms, and an understanding of the implications of one's actions for people from different cultures (Huang et al., 2014). The aspects of mindfulness already mentioned regarding inter-personal adaptability are likely to pertain to cultural adaptability: enhanced empathy, and better regulations of emotions and behaviour. In addition, some mindfulness scholars have advanced the concept of 'interbeing' in which mindfulness reduces the social and cultural barriers between people (King \& Badham, 2020). It is therefore proposed that:

H7: Mindfulness is positively related to cultural adaptability.

The I-ADAPT theory proposes individual adaptability as a second-order factor that has as its lower dimensions the factors mentioned in the previous hypotheses and is defined as 'an individual's ability, skill, disposition, willingness, and/or motivation to change or fit different task, social, and environmental features'. The theory also holds that individual adaptability is determined by a composite set of KSAOs that include cognitive ability, certain personality traits, preferences and stress and coping skills (Ployhart \& Bliese, 2006). It is proposed that mindfulness is a distal KSAO that impacts individual adaptability, because of its effects on the functional domains of cognition, emotion, behaviour and physiology (Good et al., 2016). In addition to the hypotheses regarding the sub-dimensions of individual adaptability, it is therefore also proposed that:

H8: Individual adaptability is a latent second-order construct with sub-dimensions, and is positively related to mindfulness.

\section{Method Participants and procedures}

This was a cross-sectional study to test the proposed hypotheses. Data were collected from 198 respondents using an online questionnaire. Participants who met the criteria of working in a dynamic context were approached by email, LinkedIn and Facebook. In total 2194 individuals were approached, producing 255 responses and 198 qualified responses. The overall response rate was $12 \%$ and the completion rate was $87 \%$. Informed consent was obtained from all individual participants included in the study. Ethical guidelines provided by the university were strictly followed.

The sample was diverse in terms of gender, age and tenure: $56 \%$ were female and one respondent was transgender; they ranged in age from under 30 (11\%), 30-39 (53\%) and 40-49 $(27 \%)$, to 50 years and older $(10 \%) ; 25 \%$ had been with their organisation for less than 2 years, 30\% between 2 and 5 years and $23 \%$ from 6 to 9 years. Participants held a variety of levels of seniority: $23 \%$ were specialists, $15 \%$ were senior specialists, $18 \%$ were junior managers, $21 \%$ were senior managers, $9 \%$ were heads of department and 16\% were executives.

In terms of where the sample was drawn from, 35\% were employees of a South African Internet video-streaming company facing an aggressive market entrant and undergoing a restructure. Twenty-six percent were executive MBA (Master of Business Administration) students juggling fulltime work and study at a South African university. A further group (39\%) worked in highly dynamic work contexts in South Africa where disruption and change were the norm these industries included telecom, financial services, digital advertising and media.

In terms of their workplace location, although not specifically asked for in the survey, it was expected that most of the employees worked at an office rather than at home. They were not expected to be teleworking. This research was undertaken before the COVID-19 pandemic and the disruptions that occurred to established working routines. In the future, the impact of these disruptions at the emergence of wider work-from-home routines should be studied.

\section{Measures}

\section{Mindfulness}

The MAAS (Brown, \& Ryan, 2003), a 15-question instrument, was used to measure mindfulness $(\mathrm{a}=0.89)$. Respondents say how often they experience each statement, using a sixpoint Likert scale, where high scores reflect more mindfulness. The psychometric reliability and validity of the MAAS have been proven through exploratory factor analysis and confirmatory factor analysis (Brown \& Ryan, 2003). With more than 5000 citations, MAAS is by far the most cited measure of mindfulness (Van Dam et al., 2018). It is recommended for measuring mindfulness in the workplace 
in a comprehensive review of studies by the Journal of Management (Good et al., 2016).

\section{Individual adaptability}

An adapted version of the I-ADAPT-M scale (Ployhart \& Bliese, 2006) was used to measure seven aspects of individual adaptability: work-stress adaptability $(\alpha=0.80)$; crisis adaptability $(\alpha=0.79)$; uncertainty adaptability $(\alpha=0.64)$; learning adaptability $(\alpha=0.81)$; problem-solving adaptability ( $\alpha=0.78)$; interpersonal adaptability $(\alpha=0.74)$ and cultural adaptability ( $\alpha=0.75)$. The I-ADAPT-M scale includes questions such as 'I enjoy learning new approaches for conducting work', and uses a six-point Likert scale ranging from 1 (strongly disagree) to 6 (strongly agree). The I-ADAPT-M is based on a thoroughly developed theoretical model which relates trait adaptability to individual performance in dynamic environments. The authors of the I-ADAPT-M have demonstrated construct validity (Ployhart \& Bliese, 2006). Two studies have demonstrated the reliability and validity of subsets of the scale, and found it to predict job satisfaction and performance (Baard et al., 2014). However, the I-ADAPT as a whole has only been empirically tested in one other study of which the authors are aware (Hamtiaux et al., 2013).

\section{Ethical considerations}

This research project was conducted after receiving ethical clearance from the Ethics Committee of the Gordon Institute of Business Science, University of Pretoria. The ethical clearance process was followed by researchers and an ethical clearance letter was provided on 17 August 2018.

\section{Results}

Our study confirmed hypotheses $\mathrm{H} 1$ to $\mathrm{H} 5$ and rejected hypotheses $\mathrm{H} 6$ and $\mathrm{H} 7$. It also rejected hypothesis $\mathrm{H} 8$. As the data did not exhibit univariate normality, the models were estimated with the MLM estimator, a maximum likelihood parameter within the MPlus statistical modelling program that is robust to non-normality (Muthén \& Muthén, 2017). The estimates for the paths in the model are reported (Table 1). Mindfulness explained the variance in work-stress adaptability (0.44), uncertainty adaptability (0.28), crisis adaptability (0.25) and problem-solving adaptability (0.23), all $p<0.01$. Mindfulness was also positively related to learning adaptability $(0.19, p<0.05)$. There was no significant relationship between mindfulness and inter-personal adaptability or cultural adaptability.

\begin{tabular}{lccccc} 
TABLE 1: Standardised estimates in the structural model. \\
\hline Path & $\begin{array}{c}\text { Standardised } \\
\text { estimate }\end{array}$ & $\begin{array}{c}\text { Standard } \\
\text { error } \\
\text { estimate }\end{array}$ & $\boldsymbol{t}$ & $\boldsymbol{p}$ \\
\hline Mindfulness $\rightarrow$ Work-stress adaptability & 0.44 & 0.07 & 6.478 & $0.000^{* *}$ \\
Mindfulness $\rightarrow$ Crisis adaptability & 0.25 & 0.07 & 3.499 & $0.000^{* *}$ \\
Mindfulness $\rightarrow$ Uncertainty adaptability & 0.28 & 0.09 & 3.159 & $0.002^{* *}$ \\
Mindfulness $\rightarrow$ Learning adaptability & 0.19 & 0.08 & 2.410 & $0.016^{*}$ \\
Mindfulness $\rightarrow$ Problem-solving adaptability & 0.23 & 0.08 & 3.013 & $0.003^{* *}$ \\
Mindfulness $\rightarrow$ Inter-personal adaptability & 0.05 & 0.08 & 0.608 & 0.543 \\
Mindfulness $\rightarrow$ Cultural adaptability & 0.11 & 0.08 & 1.404 & 0.160 \\
\hline
\end{tabular}

$*$, Significant at $<0.05 ; * *$, Significant at $<0.01$.
Prior to testing the structural model, sufficient evidence was found for construct reliability and validity in the measurement model. After initial tests of the measurement model, several items were removed which had factor loadings less than 0.6. The re-estimated measurement model fitted the data well. Composite reliability and Cronbach's alpha scores were $>0.7$ for all variables, except uncertainty adaptability (Table 2). However, removing indicators did not increase reliability further in uncertainty adaptability and the average variance explained (AVE) was acceptable. Three dimensions of adaptability had marginal AVE results.

By examining the square root of the AVE and by using Satorra-Bentler chi-square difference, adequate discriminant validity was found for all the constructs.

To test hypothesis H8, first the factor structure for the individual adaptability construct was determined. Two measurement models were estimated and their Bayesian information criterion (BIC) values were compared. Bayesian information criterion takes into account the balance between fit and complexity; hence, the model with the lowest BIC is considered to be the best (Van de Schoot, Lugtig, \& Hox, 2012). The first measurement model $(B I C=11$ 206.413) estimated individual adaptability as a second-order reflective construct with seven underlying dimensions as indicators of individual adaptability. In contrast, the second measurement model (BIC $=11$ 186.489) estimated the aforementioned seven dimensions as first-order reflective constructs. Considering that the second measurement model had a smaller BIC value, the hypothesis was not supported. This means that whilst the underlying factors of individual adaptability are worth understanding in terms of their individual influence on workplace dynamics, it was found that they did not aggregate into a higher order construct called 'individual adaptability'.

\section{Conclusion}

\section{Theoretical implications}

Given the large number of studies empirically confirming the link between mindfulness and stress management (Brown \& Ryan, 2003; Brown et al., 2007; Kabat-Zinn, 2003; Lomas et al., 2017), the confirmation of hypothesis H1 was not surprising. However, the reported effect size and study context were significant and serve to underline the value of mindfulness in supporting resilience and coping strategies in dynamic work contexts.

TABLE 2: Construct validity and reliability for re-estimated measurement model. Constructs and items $\quad$ AVE Composite reliability Cronbach's alpha

\begin{tabular}{llll}
\hline Mindfulness & 0.59 & 0.90 & 0.90
\end{tabular}

$\begin{array}{llll}\text { Work-stress adaptability } & 0.62 & 0.83 & 0.80\end{array}$

$\begin{array}{llll}\text { Crisis adaptability } & 0.57 & 0.80 & 0.79\end{array}$

$\begin{array}{llll}\text { Uncertainty adaptability } & 0.53 & 0.68 & 0.64\end{array}$

$\begin{array}{llll}\text { Learning adaptability } & 0.48 & 0.82 & 0.81\end{array}$

$\begin{array}{llll}\text { Problem-solving adaptability } & 0.47 & 0.78 & 0.78\end{array}$

$\begin{array}{llll}\text { Inter-personal adaptability } & 0.49 & 0.74 & 0.74\end{array}$

\begin{tabular}{llll} 
Cultural adaptability & 0.51 & 0.76 & 0.75 \\
\hline
\end{tabular}

AVE, average variance explained. 
The positive relationships found between mindfulness and the second-order constructs of crisis adaptability, uncertainty adaptability, learning adaptability and problem-solving adaptability (hypotheses $\mathrm{H} 2, \mathrm{H} 3, \mathrm{H} 4$ and $\mathrm{H} 5$ ) suggest that mindfulness is not just a coping skill that moderates stress and supports wellness, but it is a potential tool for improving performance and business outcomes in dynamic situations. An area for further research would be to investigate the link between these aspects of individual adaptability (crisis, uncertainty, learning and problem-solving adaptability) and adaptive performance itself (Huang et al., 2014; Jundt et al., 2015). This would require a satisfactory measure of behaviour, for example, supervisor ratings or a laboratory test of behaviour (Baard et al., 2014; Bell \& Kozlowski, 2008; Good, 2014). The relationships between mindfulness, adaptability and adaptive performance could then be further clarified.

The non-findings on hypotheses $\mathrm{H} 6$ and $\mathrm{H} 7$ raise intriguing questions around the conceptualisationand operationalisation of mindfulness. It is possible that whilst the scale used in this study (i.e. MAAS; Brown \& Ryan, 2003) is the most commonly used scale in empirical mindfulness research, its unidimensional definition of mindfulness impacts the measurement of potentially correlated workplace constructs related to interpersonal empathy.

The creators of MAAS explicitly exclude attitudinal aspects of mindfulness (Brown \& Ryan, 2003); however, a number of theoretical discussions of mindfulness suggest that mindfulness can be better operationalised by including an attitude of empathy and inter-personal sensitivity (Bishop et al., 2004; Crane et al., 2017; Kabat-Zinn, 2003; Shapiro et al., 2006). There are also empirical studies that have related mindfulness training to increased pro-social behaviour and compassion (Singer \& Engert, 2019).

Future research on individual adaptability could therefore employ other mindfulness scales which attempt to capture a more expanded operationalisation of mindfulness, such as the Freiburg Mindfulness Inventory (Buchheld, Grossman, \& Wallach, 2001) and the Five-Facet Mindfulness Questionnaire (Baer, Smith, Hopkins, Krietemeyer, \& Toney, 2006). This will help determine if the non-finding with regards interpersonal and cultural adaptability is because of the scale used, mindfulness itself or the context studied.

In terms of the context studied, another possible reason for the non-finding is that the I-ADAPT-M scale has not been used in an African population before. Because of cultural attitude towards interpersonal relationships and mutual support, such as the notion of Ubuntu (Adonisi, 1993) and the reported collectivist orientations on the African continent (Eds. House, Hanges, Javidan, Dorfman, \& Gupta, 2004), the respondents may generally have reported high scores on the cultural and inter-personal adaptability subscale, creating a 'ceiling' effect. Inter-personal adaptability $(M=4.97)$ and cultural adaptability ( $M=5.18)$ received the highest mean scores out of the adaptability constructs and were scored significantly higher than mindfulness $(M=3.94)$; this ceiling effect may have reduced the variability between scores on these dimensions and eliminated any significant correlations. An important area for future research would be to investigate the contextual factors which may influence respondents when measuring inter-personal and cultural adaptability and mindfulness.

There may be a network of effects rather than simple linear relationships. This has been discussed by Ployhart and Bliese (2006). Being adaptable can sometimes mean a person is agile in anticipating change. This might lead a person to introduce more change in the workplace, which could in turn increase the amount of stress. It has been proposed that ability to adapt to changes in the workplace may also be responsible for generating workplace stress (Braun et al., 2017). A recent study demonstrated that mindfulness can moderate the potentially negative effects on innovation (a form of adaptive performance) of low-activated negative effects, that is, feelings of sadness, unhappiness and hopelessness (Montani et al., 2018). An area for further research, therefore, would be to measure objective work stress and performance in a sample and to better investigate the potential network of effects.

This is only the second study to empirically test the I-ADAPT-M scale, and so the lack of support for a secondorder individual adaptability construct in this sample is an important addition to the literature of adaptability. This finding may be unique to the sample, and further research could perhaps find support for the second-order construct in other samples. Or it may be a result of adaptations made to the scale; in order to enhance response rates, the I-ADAPT scale was shortened to 35 items, and further research might look into testing this and other shortened versions in new samples to purify the scale further. Alternatively, the finding may perhaps point to a more complex higher-order structure. The I-ADAPT theory describes two kinds of adaptive interaction with the environment: in static environments, adaptable individuals proactively seek to change; whereas in dynamic environments, adaptable individuals are more reactive (Ployhart \& Bliese, 2006). Therefore, it is possible that there are two latent second-order constructs related to proactive and reactive forms of individual adaptability. Further work is required to explore this potential higher-order structure.

\section{Practical implications}

The findings of this study predict that developing the skill of mindfulness will improve various aspects of adaptability (crisis, uncertainty, learning and problem-solving adaptability) leading to improved adaptive performance. Given the dynamic nature of many work contexts and need for individual adaptability, practical interventions could be sought to increase mindfulness in the workplace.

Mindfulness-based interventions such as 'mindfulness-based stress reduction' have established protocols with proven outcomes for increasing mindfulness (Brown et al., 2007; Crane et al., 2017; Kabat-Zinn, 2003; Lomas et al., 2017). However, conducting such programmes in the workplace 
can also entail significant expense and time. It may include protocols that are over-focussed on stress and medical outcomes, and may not be compatible with a company's culture (Hales, Kroes, Chen, \& David Kang, 2012; Vich, 2015). More appropriate variations of the original MBI format are required for company settings which focus on performance enhancement (adaptability) in addition to well-being (stressmanagement support). In addition, delivery mechanisms that reduce cost and/or time impacts and allow for self-study would be more suitable than programmes that rely exclusively on trainer-delivered, in-person instruction.

Online MBIs are a recent development and potential solution to many of these issues. However, they have largely been trialled in clinical settings (Cavanagh et al., 2018; Spijkerman, Pots, \& Bohlmeijer, 2016). Several concerns have also been raised about the effectiveness, appropriateness and ethics of online MBI delivery (Davidson \& Dahl, 2018; Van Dam et al., 2018). These concerns need to be adequately addressed by programme design, content and digital delivery methods.

\section{Directions for future research}

Self-report scales have their limitations (Arnold \& Feldman, 1981; Conway \& Lance, 2010). In further research, neuroimaging (Goleman \& Davidson, 2017) or behavioural measures of mindfulness such as breath-counting (Levinson, Stoll, Kindy, Merry, \& Davidson, 2014) could be employed to further address this limitation.

Limited data on tenure were collected for this study, which did not allow for advanced statistical analysis. Future studies could examine the possible influence of expertise on the relationship between mindfulness and adaptability. Contingency theory suggests that experts would benefit from mindfulness in novel situations, but that novices could actually see performance decrements (Dane, 2010).

Future researchers are encouraged to examine the cultural dimensions that may impact on mindfulness and individual adaptability in the African context. Additional control variables such as collectivism-individualism (Triandis, 2001) could be included. Nkomo (2011) has demonstrated the complex tensionfilled but important terrain of better linking African contexts and realities with Western theory. Work on mindfulness in South Africa has shown its relevance in culturally embedded settings (McIntyre, Elkonin, De Kooker, \& Magidson, 2018).

Future research can also add the perspective of Human Resources (HR) managers to complement the individual level self-reporting. The views of HR managers may support, contradict or add nuance to the findings reported here. Mindfulness has been shown to be attractive to HR managers as a tool for improving performance but there are concerns around its effectiveness (Altizer, 2017).

Future researchers can further build on the findings here and extend the causal conclusions through experimental, longitudinal studies that implement an MBI, with appropriate controls (Crane, 2019), and also include performance and wellbeing measures. The full nomological network could then be described in detail. For example, the I-ADAPT theory suggests an alternative explanation for the mindfulness-adaptability relationship: that mindfulness may be a mediator between adaptability and performance itself, instead of (or in addition to) being a KSAO of adaptability (Cullen et al., 2014). Increased mindfulness may also aid the process through which individual level adaptability interacts with more proximal factors, for example, organisational structure and culture (Ployhart \& Bliese, 2006), to create adaptive performance at the individual team and organisational level. In addition, as the lack of support for a second-order individual adaptability construct suggests a potentially more complex interplay between mindfulness, adaptability and performance or wellbeing outcomes, a more comprehensive longitudinal study of the entire mindful adaptive performance model, involving an MBI, could help determine the nature of constructs examined.

In closing, this study measured mindfulness and individual adaptability in a sample of workers in dynamic contexts. The study found a positive relationship between mindfulness and the sub-dimensions of work-stress adaptability, uncertainty adaptability, crisis adaptability, learning adaptability and problem-solving adaptability. This suggests an important role for mindfulness in promoting adaptability in dynamic contexts and that mindfulness is not simply a stress-management skill, but also enhances other aspects of adaptability such as learning and problem-solving. These findings and the literature suggest that the positive effects of mindfulness on both performance and well-being may be explained by its positive relationship with both these aspects of adaptability. The unidimensional operationalisation of mindfulness used in this study was not found to be correlated to inter-personal and cultural adaptability, despite support from some literature on mindfulness. This finding may result from contextual considerations but it more likely affirms the need for broader measures of mindfulness that include attitudinal aspects.

\section{Acknowledgements}

The authors would like to thank all respondents who took part in the survey.

\section{Competing interests}

The authors have declared that no competing interests exist.

\section{Authors' contributions}

The two authors worked closely together for the period of the research from conceptualisation through to final submission. R.J. initially conceptualised the work under the supervision of A.W-P. The data for analysis was sourced by R.J. Both authors worked together to ensure the statistical analysis was correctly undertaken. They worked closely together to ensure the key learnings were highlighted and summarised. R.J. prepared the draft reports and manuscripts and A.W-P. reviewed that work and proposed changes when needed. Both authors signed off on the final submission. 


\section{Funding information}

This research received no specific grant from any funding agency in the public, commercial or not-for-profit sectors.

\section{Data availability}

The data that support the findings of this study are available from the corresponding author, A.W-P., upon reasonable request.

\section{Disclaimer}

The views and opinions expressed in this article are those of the authors and do not necessarily reflect the official policy or position of any affiliated agency of the authors.

\section{References}

Adonisi, M. (1993). African management - The career in community. In P. Christie, R Lessem \& L. Mbigi (Eds.), African management: Philosophies, concepts and applications (pp. 309-314). Randburg: Knowledge Resources.

Altizer, C. (2017). Mindfulness: Performance, wellness or fad?. Strategic HR Review, 16(1), 24-31. https://doi.org/10.1108/SHR-10-2016-0093

Allworth, E., \& Hesketh, B. (1999). Construct-oriented biodata: Capturing change-related and contextually relevant future performance. International Journal of Selection and Assessment, 7(2), 97-111. https://doi.org/10.1111/1468-2389.00110

Arnold, H.J., \& Feldman, D.C. (1981). Social desirability response bias in self-report choice situations. Academy of Management Journal, 24(2), 377-385. https://doi. org/10.2307/255848

Autor, D.H. (2015). Why are there still so many jobs? The history and future of workplace automation. Journal of Economic Perspectives, 29(3), 3-30. https://doi. org/10.1257/jep.29.3.3

Baard, S.K., Rench, T.A., \& Kozlowski, S.W.J. (2014). Performance adaptation: A theoretical integration and review. Journal of Management, 40(1), 48-99. https:// theoretical integration and review. Jo

Baer, R.A., Smith, G.T., Hopkins, J., Krietemeyer, J., \& Toney, L. (2006). Using self-report assessment methods to explore facets of mindfulness. Assessment, 13(1), 27-45. https://doi.org/10.1177/1073191105283504

Bell, B.S., \& Kozlowski, S.W.J. (2008). Active learning: Effects of core training design elements on self-regulatory processes, learning, and adaptability. Journal of Applied Psychology, 93(2), 296-316. https://doi.org/10.1037/0021 9010.93.2.296

Bergman, M.E., Donovan, M.A., Drasgow, F., Overton, R.C., \& Henning, J.B. (2008) Test of Motowidlo et al.'s (1997) theory of individual differences in task and contextual performance. Human Performance, 21(3), 227-253. https://doi. org/10.1080/08959280802137606

Bishop, S.R., Lau, M., Shapiro, S., Carlson, L., Anderson, N.D., Carmody, J., Devins, G. (2004). Mindfulness: A proposed operational definition. Clinical
Psychology: Science and Practice, 11(3), 230-241. https://doi.org/10.1093/ Psychology: $\mathrm{Sc}$
clipsy/bph077

Bohle Carbonell, K., Könings, K.D., Segers, M., \& Van Merriënboer, J.J.G. (2016). Measuring adaptive expertise: Development and validation of an instrument European Journal of Work and Organizational Psychology, 25(2), 167-180. https://doi.org/10.1080/1359432X.2015.1036858

Braun, T.J., Hayes, B.C., DeMuth, R.L.F., \& Taran, O.A. (2017). The development, validation, and practical application of an employee agility and resilience measure to facilitate organizational change. Industrial and Organizational Psychology, 10(4), 703-723. https://doi.org/10.1017/iop.2017.79

Brewer, J.A., Sinha, R., Chen, J.A., Michalsen, R.N., Babuscio, T.A., Nich, C., .. Rounsaville, B.J. (2009). Mindfulness training and stress reactivity in substance abuse: Results from a randomized, controlled stage I pilot study. Substance Abuse 30(4), 306-317. https://doi.org/10.1080/08897070903250241

Brown, K.W., \& Ryan, R.M. (2003). The benefits of being present: Mindfulness and its role in psychological well-being. Journal of Personality and Social Psychology, 84(4), 822-848. https://doi.org/10.1037/0022-3514.84.4.822

Brown, K.W., Ryan, R.M., \& Creswell, J.D. (2007). Mindfulness: Theoretical foundations and evidence for its salutary effects. Psychological Inquiry, 18(4), 211-237. https://doi.org/10.1080/10478400701598298

Buchheld, N., Grossman, P., \& Walach, H. (2001). Measuring mindfulness in insight meditation (Vipassana) and meditation-based psychotherapy: The development of the Freiburg Mindfulness Inventory (FMI). Journal for Meditation and Meditation Research, 1(1), 11-34.

Campbell, J.P. (1990). Modeling the performance prediction problem in industrial and organizational psychology. In M.D. Dunnette \& L.M. Hough (Eds.), Handbook of industrial and organizational psychology (pp. 687-732). Palo Alto, CA: Consulting Psychologists Press, Inc.

Campbell, J.P., McCloy, R.A., Oppler, S.H., \& Sager, C.E. (1993). A theory of performance. In N. Schmitt \& W.C. Borman (Eds.), Personnel selection in organizations (pp. 35-69). San Francisco, CA: Jossey-Bass.
Cavanagh, K., Churchard, A., O’Hanlon, P., Mundy, T., Votolato, P., Jones, F., ... Strauss, C. (2018). A randomised controlled trial of a brief online Mindfulness-Based Intervention in a non-clinical population: Replication and extension. Mindfulness, 9(4), 1191-1205. https://doi.org/10.1007/s12671-017-0856-1

Colzato, L.S., Ozturk, A., \& Hommel, B. (2012). Meditate to create: The impact of focused-attention and open-monitoring training on convergent and divergent thinking. Frontiers in Psychology, 3, 1-5. https://doi.org/10.3389/fpsyg.2012.00116

Conway, J.M., \& Lance, C.E. (2010). What reviewers should expect from authors regarding common method bias in organizational research. Journal of Business and Psychology, 25(3), 325-334. https://doi.org/10.1007/s10869-010-9181-6

Crane, R.S. (2019). Intervention integrity in mindfulness-based research: Strengthening a key aspect of methodological rigor. Current Opinion in Psychology, 28, 1-5. https://doi.org/10.1016/j.copsyc.2018.09.009

Crane, R.S., Brewer, J., Feldman, C., Kabat-Zinn, J., Santorelli, S., Williams, J.M.G., \& Kuyken, W. (2017). What defines mindfulness-based programs? The warp and the weft. Psychological Medicine, 47(6), 990-999. https://doi.org/10.1017/ S0033291716003317

Csikszentmihalyi, M. (2014). Flow and the foundations of positive psychology (pp. 209-226). Dordrecht: Springer.

Cullen, K.L., Edwards, B.D., Casper, W.C., \& Gue, K.R. (2014). Employees' adaptability and perceptions of change-related uncertainty: Implications for perceived organizational support, job satisfaction, and performance. Journal of Business and Psychology, 29(2), 269-280. https://doi.org/10.1007/s10869-013-9312-y

Dane, E. (2010). Reconsidering the trade-off between expertise and flexibility: A cognitive entrenchment perspective. Academy of Management Review, 35(4), 579-603. https://doi.org/10.5465/AMR.2010.53502832

Dane, E. (2011). Paying attention to mindfulness and its effects on task performance in the workplace. Journal of Management, 37(4), 997-1018. https://doi. org/10.1177/0149206310367948

Dane, E., \& Brummel, B.J. (2014). Examining workplace mindfulness and its relations to job performance and turnover intention. Human Relations, 67(1), 105-128. https://doi.org/10.1177/0018726713487753

Davidson, R.J., \& Dahl, C.J. (2018). Outstanding challenges in scientific research on mindfulness and meditation. Perspectives on Psychological Science, 13(1), 62-65. https://doi.org/10.1177/1745691617718358

Donald, J.N., Bradshaw, E.L., Ryan, R.M., Basarkod, G., Ciarrochi, J., Duineveld, J.J., ... Sahdra, B.K. (2020). Mindfulness and its association with varied types of motivation: A systematic review and meta-analysis using self-determination theory. Personality and Social Psychology Bulletin, 46(7), 1121-1138. https://doi. org/10.1177/0146167219896136

Eisenhardt, K.M., \& Martin, A.J. (2000). Dynamic capabilities: What are they? Strategic Management Journal, 21(10-11), 1105-1121. https://doi.org/10.1002/10970266(200010/11)21:10/11<1105::AID-SMJ133>3.0.CO;2-E

Glomb, T.M., Duffy, M.K., Bono, J.E., \& Yang, T. (2011). Mindfulness at work. In A. Joshi, H. Liao, \& J.J. Martocchio (Eds.), Research in personnel and human resources management (Vol. 30, pp. 115-157). Emerald Group Publishing Ltd. https://doi. org/10.1108/S0742-7301(2011)0000030005

Goh, J., Pfeffer, J., \& Zenios, S.A. (2016). The relationship between workplace stressors and mortality and health costs in the United States. Management Science, 62(2), 608-628. https://doi.org/10.1287/mnsc.2014.2115

Goleman, D., \& Davidson, R.J. (2017). Altered traits: Science reveals how meditation changes your mind, brain, and body. New York, NY: Penguin Random House.

Good, D. (2014). Predicting real-time adaptive performance in a dynamic decisionmaking context. Journal of Management and Organization, 20(6), 715-732. https://doi.org/10.1017/jmo.2014.54

Good, D.J., Lyddy, C.J., Glomb, T.M., Bono, J.E., Brown, K.W., Duffy, M.K., ... Lazar, S.W. (2016). Contemplating mindfulness at work. Journal of Management, 42(1), 114-142. https://doi.org/10.1177/0149206315617003

Griffin, M.A., Neal, A., \& Parker, S.K. (2007). A new model of work role performance: Positive behavior in uncertain and interdependent contexts. Academy of Management Journal, 50(2), 327-347. https://doi.org/10.5465/AMJ.2007.24634438

Hales, D.N., Kroes, J., Chen, Y., \& David Kang, K.W. (2012). The cost of mindfulness: A case study. Journal of Business Research, 65(4), 570-578. https://doi. org/10.1016/j.jbusres.2011.02.023

Hamtiaux, A., Houssemand, C., \& Vrignaud, P. (2013). Individual and career adaptability: Comparing models and measures. Journal of Vocational Behavior, 83(2), 130-141. https://doi.org/10.1016/j.jvb.2013.03.006

Helfat, C.E., \& Peteraf, M.A. (2015). Managerial cognitive capabilities and the microfoundations of dynamic capabilities. Strategic Management Journal, 36(6) 831-850. https://doi.org/10.1002/smj.2247

House, R.J., Hanges, P.J., Javidan, M., Dorfman, P.W., \& Gupta, V. (Eds.). (2004) Culture, leadership, and organizations: The GLOBE study of 62 societies. Thousand Oaks, CA: Sage.

Huang, J.L., Ryan, A.M., Zabel, K.L., \& Palmer, A. (2014). Personality and adaptive performance at work: A meta-analytic investigation. Journal of Applied Psychology, 99(1), 162-179. https://doi.org/10.1037/a0034285

Hue, M., \& Lau, N. (2015). Promoting well-being and preventing burnout in teacher education: A pilot study of a mindfulness-based programme for pre-service teachers in Hong Kong. Teacher Development, 19(3), 381-401. https://doi.org/10 $.1080 / 13664530.2015 .1049748$

Hülsheger, U.R., Alberts, H.J.E.M., Feinholdt, A., \& Lang, J.W.B. (2013). Benefits of mindfulness at work: The role of mindfulness in emotion regulation, emotional
exhaustion, and job satisfaction. Journal of Applied Psychology, 98(2), 310-325. exhaustion, and job satisfaction. Jour
https://doi.org/10.1037/a0031313 
Hülsheger, U.R., Walkowiak, A., \& Thommes, M.S. (2018). How can mindfulness be promoted? Workload and recovery experiences as antecedents of daily fluctuations in mindfulness. Journal of Occupational and Organizational Psychology, 91(2). https://doi.org/10.1111/joop.12206

Hyland, P.K., Andrew Lee, R., \& Mills, M.J. (2015). Mindfulness at work: A new approach to improving individual and organizational performance. Industrial and Organizational Psychology, 8(4), 576-602. https://doi.org/10.1017/iop.2015.41

Jha, A.P., Morrison, A.B., Dainer-Best, J., Parker, S., Rostrup, N., \& Stanley, E.A. (2015). Minds 'at attention': Mindfulness training curbs attentional lapses in military cohorts. PLoS One, 10(2), 1-20. https://doi.org/10.1371/journal.pone.0116889

Jha, A.P., Stanley, E.A., Kiyonaga, A., Wong, L., \& Gelfand, L. (2010). Examining the protective effects of mindfulness training on working memory capacity and affective experience. Emotion, 10(1), 54-64. https://doi.org/10.1037/a0018438

Johnson, K.R., Park, S., \& Chaudhuri, S. (2020). Mindfulness training in the workplace: Exploring its scope and outcomes. European Journal of Training and Development, 44(4-5), 341-354. https://doi.org/10.1108/EJTD-09-2019-0156

Jundt, D.K., Shoss, M.K., \& Huang, J.L. (2015). Individual adaptive performance in organizations: A review. Journal of Organizational Behavior, 36(S1), S53-S71. https://doi.org/10.1002/job.1955

Kabat-Zinn, J. (1982). An outpatient program in behavioral medicine for chronic pain patients based on the practice of mindfulness meditation: Theoretical considerations and preliminary results. General Hospital Psychiatry, 4(1), 33-47. considerations and preliminary results. General
https://doi.org/10.1016/0163-8343(82)90026-3

Kabat-Zinn, J. (2003). Mindfulness-based interventions in context: Past, present, and future. Clinical Psychology: Science and Practice, 10(2), 144-156. https://doi. org/10.1093/clipsy.bpg016

King, E., \& Badham, R. (2020). The wheel of mindfulness: A generative framework for second-generation mindful leadership. Mindfulness, 11, 166-176. https://doi. org/10.1007/s12671-018-0890-7

King, E., \& Haar, J.M. (2017). Mindfulness and job performance: A study of Australian leaders. Asia Pacific Journal of Human Resources, 55(3), 298-319. https://doi. org/10.1111/1744-7941.12143

Kotter, J.P. (2012, November). Accelerate! Harvard Business Review, pp. 1-17. Retrieved from http://hbr.org/2012/11/accelerate/ar/1

Krumm, S., Kanthak, J., Hartmann, K., \& Hertel, G. (2016). What does it take to be a virtual team player? The knowledge, skills, abilities, and other characteristics

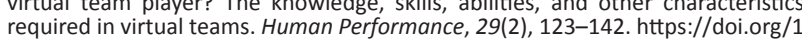
required in virtual teams. Human

Kuechler, W., \& Stedham, Y. (2018). Management education and transformational learning: The integration of mindfulness in an MBA course. Journal of Management Education, 42(1), 8-33. https://doi.org/10.1177/1052562917727797

Le Pine, J.A., Colquitt, J.A., \& Erez, A. (2000). Adaptability to changing task contexts: Effects of general cognitive ability, conscientiousness, and openness to experience. Personnel Psychology, 53(3), 563-593. https://doi.org/10.1111/j.1744-6570.2000. tb00214.x

LePine, J.A., Hollenbeck, J.R., Ilgen, D.R., \& Hedlund, J. (1997). Effects of individual differences on the performance of hierarchical decision-making teams: Much more than g. Journal of Applied Psychology, 82(5), 803. https://doi. org/10.1037/0021-9010.82.5.803

Levinson, D.B., Stoll, E.L., Kindy, S.D., Merry, H.L., \& Davidson, R.J. (2014). A mind you can count on: Validating breath counting as a behavioral measure of mindfulness. Frontiers in Psychology, 5, 1202. https://doi.org/10.3389/fpsyg.2014.01202

Lindahl, J.R., Fisher, N.E., Cooper, D.J., Rosen, R.K., \& Britton, W.B. (2017). The varieties of contemplative experience: A mixed-methods study of meditation-related challenges in Western Buddhists. PLoS One, 12(5), e0176239. https://doi. org/10.1371/journal.pone.0176239

Lomas, T., Medina, J.C., Ivtzan, I., Rupprecht, S., Hart, R., \& Eiroa-Orosa, F.J. (2017) The impact of mindfulness on well-being and performance in the workplace: An inclusive systematic review of the empirical literature. European Journal of Work and Organizational Psychology, 26(4), 492-513. https://doi.org/10.1080/135943 2X.2017.1308924

Lyddy, C.J., \& Good, D.J. (2017). Being while doing: An inductive model of mindfulness at work. Frontiers in Psychology, 7, 1-18. https://doi.org/10.3389/fpsyg.2016.02060

Lyddy, C.J., Good, D.J., Bolino, M.C., Thompson, P.S., \& Stephens, J.P. (in press). The costs of mindfulness at work: The moderating role of mindfulness in surface acting, self-control depletion, and performance outcomes. Journal of Applied Psychology. https://doi.org/10.1037/apl0000863

McIntyre, T.L., Elkonin, D., De Kooker, M., \& Magidson, J.F. (2018). The application of mindfulness for individuals living with HIV in South Africa: A hybrid effectivenessimplementation pilot study. Mindfulness, 9(3), 871-883. https://doi.org/10.1007/ s12671-017-0827-6

Mesmer-Magnus, J., Manapragada, A., Viswesvaran, C., \& Allen, J.W. (2017). Trait mindfulness at work: A meta-analysis of the personal and professional correlate of trait mindfulness. Human Performance, 30(2-3), 79-98. https://doi.org/10.108 0/08959285.2017.1307842

Montani, F., Dagenais-Desmarais, V., Giorgi, G., \& Grégoire, S. (2018). A conservation of resources perspective on negative affect and innovative work behaviour: The role of affect activation and mindfulness. Journal of Business and Psychology 33(1), 123-139. https://doi.org/10.1007/s10869-016-9480-7

Motowidlo, S.J., Borman, W.C., \& Schmit, M.J. (1997). A theory of individual differences in task and contextual performance. Human Performance, 10(2), 71-83. https://doi.org/10.1207/s15327043hup1002_1

Motowidlo, S.J., \& Van Scotter, J.R. (1994). Evidence that task performance should be distinguished from contextual performance. Journal of Applied Psychology, 79(4), 475-480. https://doi.org/10.1037/0021-9010.79.4.475
Muthén, L.K., \& Muthén, B.O. (2017). MPlus user's guide (8th edn.). Los Angeles, CA: Muthén \& Muthén.

Nkomo, S.M. (2011). A postcolonial and anti-colonial reading of 'African' leadership and management in organization studies: Tensions, contradictions and possibilities. Organization, 18(3), 365-386. https://doi.org/10.1177/13505 08411398731

Ostafin, B.D., \& Kassman, K.T. (2012). Stepping out of history: Mindfulness improves insight problem solving. Consciousness and Cognition, 21(2), 1031-1036. https:// doi.org/10.1016/j.concog.2012.02.014

Ployhart, R.E., \& Bliese, P.D. (2006). Individual adaptability (I-ADAPT) theory Conceptualizing the antecedents, consequences, and measurement of individual differences in adaptability. In C.S. Burke, L.G. Pierce, \& E. Salas (Eds.), Advances in human performance and cognitive engineering research Vol 6: Understanding adaptability: A prerequisite for effective performance within complexenvironments (pp. 3-39). Bingley: Emerald Group Publishing Ltd. https://doi.org/10.1016/ (pp. 3-39). Bingley: Em
S1479-3601(05)06001-7

Ployhart, R.E., \& Moliterno, T.P. (2011). Emergence of the human capital resource: A multilevel model. Academy of Management Review, 36(1), 127-150. https://doi. org/10.5465/AMR.2011.55662569

Pulakos, E.D., Arad, S., Donovan, M.A., \& Plamondon, K.E. (2000). Adaptability in the workplace: Development of a taxonomy of adaptive performance. Journal of Applied Psychology, 85(4), 612-625. https://doi.org/10.1037//0021-9010. 85.4.612

Roche, M., Haar, J.M., \& Luthans, F. (2014). The role of mindfulness and psychological capital on the well-being of leaders. Journal of Occupational Health Psychology, 19(4), 476-489. https://doi.org/10.1037/a0037183

Ruocco, A.C., \& Direkoglu, E. (2013). Delineating the contributions of sustained attention and working memory to individual differences in mindfulness. Personality and Individual Differences, 54(2), 226-230. https://doi.org/10.1016/j. paid.2012.08.037

Segal, Z.V., Williams, J.M.G., Teasdale, J.D., \& Gemar, M.C. (2002). Mindfulness-based cognitive therapy for depression: A new approach to preventing relapse. New York, NY: Guilford Press. https://doi.org/10.1080/713869628

Shapiro, S.L., Carlson, L.E., Astin, J.A., \& Freedman, B. (2006). Mechanisms of mindfulness. Journal of Clinical Psychology, 6(23), 373-386. https://doi. org/10.1002/jclp.20237

Siegel, D. (2010). The mindful therapist: A clinician's guide to mindsight and neural integration. New York, NY: W.W. Norton.

Singer, T., \& Engert, V. (2019). It matters what you practice: Differential training effects on subjective experience, behavior, brain and body in the ReSource Project. Current Opinion in Psychology, 28, 151-158. https://doi.org/10.1016/j. copsyc.2018.12.005

Spijkerman, M.P.J., Pots, W.T.M., \& Bohlmeijer, E.T. (2016). Effectiveness of online mindfulness-based interventions in improving mental health: A review and metaanalysis of randomised controlled trials. Clinical Psychology Review, 45, 102-114. https://doi.org/10.1016/j.cpr.2016.03.009

Spinelli, C., Wisener, M., \& Khoury, B. (2019). Mindfulness training for healthcare professionals and trainees: A meta-analysis of randomized controlled trials. Journal of Psychosomatic Research, 120, 29-38. https://doi.org/10.1016/j. jpsychores.2019.03.003

Stephens, K., Jody, L., Jahn, J., Fox, S., Charoensap-Kelly, P., Mitra, R., ... Meisenback, R. (2020). Collective sensemaking around COVID-19: Experiences, concerns, and agendas for our rapidly changing organizational lives. Management Communication Quarterly, 34(3), 426-457. https://doi.org/10.1177/0893318920934890

Tang, Y.-Y., Hölzel, B.K., \& Posner, M.I. (2015). The neuroscience of mindfulness meditation. Nature Reviews, 16(4), 213-225. https://doi.org/10.1038/ nrn3916

Teece, D.J. (2007). Explicating dynamic capabilities: The nature and microfoundations of (sustainable) enterprise performance. Strategic Management Journal, 28(13), 1319-1350. https://doi.org/10.1002/smj.640

Teece, D.J., Pisano, G., \& Shuen, A. (1997). Dynamic capabilities and strategic management. Strategic Management Journal, 18(7), 509-533. https://doi. org/10.1002/(SICI)1097-0266(199708)18:7<509::AID-SMJ882>3.0.CO;2-Z

Triandis, H.C. (2001). Individualism-collectivism and personality. Journal of Personality, 69(6), 907-924. https://doi.org/10.1111/1467-6494.696169

Van Dam, N.T., Van Vugt, M.K., Vago, D.R., Schmalzl, L., Saron, C.D., Olendzki, A., .. Meyer, D.E. (2018). Mind the hype: A critical evaluation and prescriptive agenda for research on mindfulness and meditation. Perspectives on Psychological Science, 13(1), 36-61. https://doi.org/10.1177/1745691617709589

Van de Schoot, R., Lugtig, P., \& Hox, J. (2012). A checklist for testing measurement invariance. European Journal of Developmental Psychology, 9(4), 486-492. https://doi.org/10.1080/17405629.2012.686740

Venkatesh, V. (2020). Impacts of COVID-19: A research agenda to support people in their fight. International Journal of Information Management, 55, 102197. https://doi.org/10.1016/j.ijinfomgt.2020.102197

Vich, M. (2015). The emerging role of mindfulness research in the workplace and its challenges. Central European Business Review, 4(3), 35-47. https://doi. org/10.18267/j.cebr.131

Wee, E.X.M., \& Taylor, M.S. (2018). Attention to change: A multilevel theory on the process of emergent continuous organizational change. Journal of Applied Psychology, 103(1), 1-13. https://doi.org/10.1037/apl0000261

Wernerfelt, B. (1984). A resource-based view of the firm. Strategic Management Journal, 5(2), 171-180. https://doi.org/10.1002/smj.4250050207 